\title{
A nation-wide multicenter 10-year (1999-2008) retrospective study of chemotherapy in Chinese breast cancer patients
}

\author{
Qiao Li ${ }^{1}$, Zhao Yang ${ }^{2}$, Jinhu Fan ${ }^{2}$, Jianjun $\mathrm{He}^{3}$, Bin Zhang ${ }^{4}$, Hongjian Yang ${ }^{5}$, Xiaoming \\ $\mathrm{Xie}^{6}$, Zhonghua Tang ${ }^{7}$, Hui $\mathbf{L i}^{8}$, Youlin Qiao ${ }^{2}$ and Pin Zhang ${ }^{1}$ \\ ${ }^{1}$ Department of Medical Oncology, National Cancer Center/Cancer Hospital, Chinese Academy of Medical Sciences (CAMS) \\ and Peking Union Medical College, Beijing, China \\ ${ }^{2}$ Department of Cancer Epidemiology, National Cancer Center/Cancer Hospital, Chinese Academy of Medical Sciences (CAMS) \\ and Peking Union Medical College, Beijing, China \\ ${ }^{3}$ Department of Oncology Surgery, First Affiliated Hospital, School of Medicine of Xi'an Jiaotong University, Xi'an, China \\ ${ }^{4}$ Department of Breast Surgery, Liaoning Cancer Hospital, Shenyang, China \\ ${ }^{5}$ Department of Breast Surgery, Zhejiang Cancer Hospital, Hangzhou, China \\ ${ }^{6}$ Department of Breast Oncology, Sun Yat-Sen University Cancer Center, Guangdzhou, China \\ ${ }^{7}$ Department of Breast-Thyroid Surgery, Xiangya Sencod Hospital, Central South University, Changsha, China \\ ${ }^{8}$ Department of Breast Surgery, The Second People's Hospital of Sichuan Province, Chengdu, China \\ Correspondence to: Pin Zhang, email: zhang_pin@sina.com
}

Keywords: transgelin2, SREBP, PDAC, diabetes, insulin

Received: November 21, $2016 \quad$ Accepted: February 28, $2017 \quad$ Published: March 22, 2017

Copyright: Li et al. This is an open-access article distributed under the terms of the Creative Commons Attribution License 3.0 (CC BY 3.0), which permits unrestricted use, distribution, and reproduction in any medium, provided the original author and source are credited.

\section{ABSTRACT}

Little information is available on the evolvement of chemotherapeutic regimens administered to Chinese females with breast cancer. We retrospectively analyzed demographic, pathological and chemotherapeutic data of 4211 breast cancer patients, who were randomly selected from representative hospitals of 7 traditional areas in China between 1999 and 2008. A total of 3271 cases $(77.7 \%)$ received adjuvant chemotherapy, 558 (13.3\%) received neoadjuvant chemotherapy, and $392(9.3 \%)$ received chemotherapy for metastatic disease. In the adjuvant setting, higher percentage of patients with younger age, advanced stage, hormone receptor (HR) negative or HER2 positive disease received chemotherapy $(P<0.001)$. The use of CMF (cyclophosphamide, methotrexate and 5-fluorouracil) in adjuvant chemotherapy decreased significantly from 1999 to 2008, while the use of anthracycline-based (without taxanes) regimens increased in the first 5 years, followed by increased use of regimens containing both anthracyclines and taxanes. Women with locally advanced disease received more neoadjuvant chemotherapy. The percentage of neoadjuvant regimens containing anthracyclines and taxanes increased during this period. In first-line chemotherapy of metastatic disease, $\mathbf{8 7 . 5 \%}$ of cases received combined chemotherapy, and platinum-based regimens were also major choices aside from anthracyclines and taxanes. In second-line chemotherapy, $\mathbf{8 0 . 3 \%}$ received combined chemotherapy, and the combination of taxane and platinum was the most common choice. In conclusion, major changes have taken place in breast cancer chemotherapy in China during this 10-year interval, which reflected the incorporation of key evidence and guidelines into Chinese medical practice. 
Table 1: Frequency distribution of chemotherapy in different settings from 1999 to 2008

\begin{tabular}{|c|c|c|c|c|c|c|c|c|c|c|c|c|c|c|c|c|c|c|c|c|c|c|}
\hline & \multicolumn{2}{|c|}{1999} & \multicolumn{2}{|c|}{2000} & \multicolumn{2}{|c|}{2001} & \multicolumn{2}{|c|}{2002} & \multicolumn{2}{|c|}{2003} & \multicolumn{2}{|c|}{2004} & \multicolumn{2}{|c|}{2005} & \multicolumn{2}{|c|}{2006} & \multicolumn{2}{|c|}{2007} & \multicolumn{2}{|c|}{2008} & \multicolumn{2}{|c|}{ Total } \\
\hline & $\mathbf{n}$ & $\%$ & $\mathbf{n}$ & $\%$ & $\mathbf{n}$ & $\%$ & $\mathbf{n}$ & $\%$ & $\mathbf{n}$ & $\%$ & $\mathbf{n}$ & $\%$ & $\mathbf{n}$ & $\%$ & $\mathbf{n}$ & $\%$ & $\mathbf{n}$ & $\%$ & $\mathbf{n}$ & $\%$ & $\mathbf{n}$ & $\%$ \\
\hline $\begin{array}{l}\text { No } \\
\text { chemotherapy }\end{array}$ & 78 & 19.35 & 64 & 18.29 & 71 & 18.83 & 48 & 14.08 & 53 & 13.59 & 49 & 11.75 & 38 & 9.36 & 62 & 13.42 & 96 & 16.9 & 67 & 13.48 & 626 & 14.87 \\
\hline Neoadjuvant & 42 & 10.42 & 29 & 8.29 & 34 & 9.02 & 51 & 14.96 & 37 & 9.49 & 82 & 19.66 & 38 & 9.36 & 87 & 18.83 & 78 & 13.73 & 80 & 16.1 & 558 & 13.25 \\
\hline Adjuvant & 299 & 74.19 & 265 & 75.71 & 290 & 76.79 & 270 & 79.18 & 305 & 78.21 & 335 & 80.34 & 333 & 82.02 & 362 & 78.35 & 431 & 75.88 & 381 & 76.66 & 3271 & 77.68 \\
\hline Metastatic & 35 & 8.68 & 35 & 10 & 32 & 8.49 & 31 & 9.09 & 47 & 12.05 & 37 & 8.87 & 44 & 10.84 & 35 & 7.58 & 62 & 10.92 & 34 & 6.84 & 392 & 9.31 \\
\hline Unknown & 14 & 3.47 & 13 & 3.71 & 8 & 2.12 & 8 & 2.35 & 13 & 3.33 & 9 & 2.16 & 19 & 4.68 & 25 & 5.41 & 15 & 2.64 & 33 & 6.64 & 157 & 3.73 \\
\hline Total & 403 & & 350 & & 377 & & 341 & & 390 & & 417 & & 406 & & 462 & & 568 & & 497 & & 4211 & \\
\hline
\end{tabular}

Table 2: Frequency distribution of chemotherapy in different settings in 7 geographic regions

\begin{tabular}{|c|c|c|c|c|c|c|c|c|c|c|c|c|c|c|c|c|}
\hline & \multicolumn{2}{|c|}{ North } & \multicolumn{2}{|c|}{ East } & \multicolumn{2}{|c|}{ South } & \multicolumn{2}{|c|}{ Northeast } & \multicolumn{2}{|c|}{ Central } & \multicolumn{2}{|c|}{ Northwest } & \multicolumn{2}{|c|}{ Southwest } & \multicolumn{2}{|c|}{ Total } \\
\hline & $\mathbf{n}$ & $\%$ & $\mathbf{n}$ & $\%$ & $\mathbf{n}$ & $\%$ & $\mathbf{n}$ & $\%$ & $\mathbf{n}$ & $\%$ & $\mathbf{n}$ & $\%$ & $\mathbf{n}$ & $\%$ & $\mathbf{n}$ & $\%$ \\
\hline No chemotherapy & 155 & 24.18 & 27 & 4.46 & 75 & 12.42 & 113 & 13.58 & 37 & 6.78 & 197 & 40.79 & 22 & 4.41 & 626 & 14.87 \\
\hline Neoadjuvant & 43 & 6.71 & 118 & 19.47 & 61 & 10.1 & 180 & 21.63 & 18 & 3.3 & 7 & 1.45 & 131 & 26.25 & 558 & 13.25 \\
\hline Adjuvant & 390 & 60.84 & 518 & 85.48 & 484 & 80.13 & 645 & 77.52 & 498 & 91.21 & 278 & 57.56 & 458 & 91.78 & 3271 & 77.68 \\
\hline Metastatic & 34 & 5.3 & 99 & 16.34 & 109 & 18.05 & 61 & 7.33 & 11 & 2.01 & 55 & 11.39 & 23 & 4.61 & 392 & 9.31 \\
\hline Unknown & 88 & 13.73 & 35 & 5.78 & 7 & 1.16 & 18 & 2.16 & 9 & 1.65 & 0 & 0 & 0 & 0 & 157 & 3.73 \\
\hline Total & 641 & & 606 & & 604 & & 832 & & 546 & & 483 & & 499 & & 4211 & \\
\hline
\end{tabular}

\section{INTRODUCTION}

Chemotherapy of breast cancer is a rapidly evolving field. In the last quarter of the previous century, the combination of CMF was demonstrated to reduce risks of recurrence and death in early breast cancer (EBC) women [1]. In the 1980s, anthracycline-based combinations were proved effective in the adjuvant setting, followed by taxanes in the 1990s [2-4]. There are agents such as capecitabine, vinorelbine, gemcitabine, or other targeted therapies that have been approved for the treatment of metastatic breast cancer (MBC) [5]. In addition, neoadjuvant chemotherapy is increasingly applied due to higher breast conserving rates and the study of novel agents and regimens [6].

At present, little was known about the evolvement and influencing factors of breast cancer chemotherapy in China. In the current analysis, we attempted to investigate the use of chemotherapeutic regimens and agents for 4211 patients selected from representative hospitals of 7 traditional regions in China between 1999 and 2008. Additionally, this study was also aimed to improve understanding about incorporation of new evidence and guidelines into Chinese practice. Due to possible selection bias of representative hospitals, the data collected in our study may not be completely identical with the reality of China.

\section{RESULTS}

A total of 4211 patients in the 7 geographically representative hospitals from 1999 to 2008 were randomly selected in this analysis. As demonstrated in Table 1, 3271 cases $(77.7 \%)$ received adjuvant chemotherapy, 558 $(13.3 \%)$ received neoadjuvant chemotherapy, and 392 $(9.3 \%)$ received chemotherapy for $\mathrm{MBC}$. The percentage of patients who received neoadjuvant chemotherapy gradually increased from $10.4 \%$ in 1999 to $16.1 \%$ in 2008, while application of chemotherapy in adjuvant and metastatic settings remained relatively stable during this 10-year period. Comparing different regions (Table 2), the percentages of adjuvant and neoadjuvant chemotherapy were the highest in the southwest area $(91.8 \%$ and $26.4 \%$, respectively) and were the lowest in the northwest (57.6\% and $1.5 \%$, respectively). The percentage of chemotherapy in metastatic setting was the highest in the south area $(18.1 \%)$ and was the lowest in the central $(2.0 \%)$.

\section{Adjuvant chemotherapy}

\section{Factors affecting adjuvant chemotherapy selection}

Logistic regression analysis was performed to evaluate factors that might affect the application of adjuvant chemotherapy (Table 3). Further multivariate analysis demonstrated that age, stage, HR and HER2 status were independent predictors in the decision-making of adjuvant chemotherapy. No significant interaction was detected among these factors.

\section{Stage}

The percentage of patients receiving adjuvant chemotherapy in stage I, II and III cases were $69.1 \%$, 
Table 3: Univariate logistic regression analysis for the use of adjuvant chemotherapy

\begin{tabular}{|c|c|c|c|c|c|c|}
\hline & $\begin{array}{c}\text { Total } \\
\text { Distribution }\end{array}$ & $\begin{array}{c}\text { Adjuvant } \\
\text { Chemotherapy }\end{array}$ & $\%$ & $\begin{array}{l}\text { No Adjuvant } \\
\text { Chemotherapy }\end{array}$ & $\%$ & P Value \\
\hline \multicolumn{7}{|l|}{ Occupation } \\
\hline Housewife & 173 & 123 & 71.1 & 50 & 28.9 & 0.195 \\
\hline Manual Worker & 1893 & 1301 & 68.8 & 592 & 31.2 & \\
\hline Mental Worker & 1137 & 768 & 67.5 & 369 & 32.5 & \\
\hline Others & 373 & 256 & 68.7 & 117 & 31.3 & \\
\hline \multicolumn{7}{|l|}{ Education } \\
\hline None & 186 & 122 & 65.7 & 64 & 34.3 & 0.005 \\
\hline Primary School & 462 & 328 & 71.0 & 134 & 29.0 & \\
\hline Middle School & 606 & 420 & 69.3 & 186 & 30.7 & \\
\hline High School & 441 & 321 & 72.8 & 120 & 27.2 & \\
\hline $\begin{array}{l}\text { University and } \\
\text { above }\end{array}$ & 396 & 296 & 74.8 & 100 & 25.2 & \\
\hline \multicolumn{7}{|l|}{ Marital Status } \\
\hline Single & 51 & 32 & 63.6 & 19 & 36.4 & 0.682 \\
\hline Married & 4090 & 2789 & 68.2 & 1301 & 31.8 & \\
\hline $\begin{array}{l}\text { Widowed/ } \\
\text { Divorced }\end{array}$ & 52 & 35 & 67.3 & 17 & 32.7 & \\
\hline \multicolumn{7}{|l|}{ Age } \\
\hline$\leq 39$ yrs & 790 & 665 & 84.2 & 125 & 15.8 & $<0.001$ \\
\hline $40-49$ yrs & 1624 & 1330 & 81.9 & 294 & 18.1 & \\
\hline $50-59 \mathrm{yrs}$ & 1147 & 912 & 79.5 & 235 & 20.5 & \\
\hline $60-69$ yrs & 483 & 317 & 65.6 & 166 & 34.4 & \\
\hline$\geq 70 \mathrm{yrs}$ & 166 & 47 & 28.3 & 119 & 71.7 & \\
\hline \multicolumn{7}{|l|}{ Stage } \\
\hline I & 663 & 458 & 69.1 & 205 & 30.9 & $<0.001$ \\
\hline II & 1891 & 1573 & 83.2 & 318 & 16.8 & \\
\hline III & 788 & 740 & 93.9 & 48 & 6.1 & \\
\hline \multicolumn{7}{|l|}{ ER/PR } \\
\hline ER- PR- & 1139 & 972 & 85.3 & 167 & 14.7 & $<0.001$ \\
\hline $\mathrm{ER}+/ \mathrm{PR}+$ & 2395 & 1924 & 80.3 & 471 & 19.7 & \\
\hline \multicolumn{7}{|l|}{ HER2 } \\
\hline Negative & 736 & 595 & 80.8 & 141 & 19.2 & $<0.001$ \\
\hline Positive & 2113 & 1742 & 82.4 & 371 & 17.6 & \\
\hline
\end{tabular}


Table 4: Percentage of patients receiving adjuvant chemotherapy according to different age groups, stages, ER/PR and HER2 status from 1999 to 2008

\begin{tabular}{lccccccccccc}
\hline & $\mathbf{1 9 9 9}$ & $\mathbf{2 0 0 0}$ & $\mathbf{2 0 0 1}$ & $\mathbf{2 0 0 2}$ & $\mathbf{2 0 0 3}$ & $\mathbf{2 0 0 4}$ & $\mathbf{2 0 0 5}$ & $\mathbf{2 0 0 6}$ & $\mathbf{2 0 0 7}$ & $\mathbf{2 0 0 8}$ & Total \\
\hline Age groups & & & & & & & & & & & \\
$\leq 39$ & $84.8 \%$ & $87.3 \%$ & $85.5 \%$ & $88.9 \%$ & $84.5 \%$ & $87.1 \%$ & $92.1 \%$ & $85.3 \%$ & $74.2 \%$ & $82.3 \%$ & $84.2 \%$ \\
$40 \sim 49$ & $74.7 \%$ & $82.3 \%$ & $83.6 \%$ & $82.4 \%$ & $85.9 \%$ & $82.2 \%$ & $87.5 \%$ & $81.4 \%$ & $82.4 \%$ & $78.2 \%$ & $81.9 \%$ \\
$50 \sim 59$ & $76.9 \%$ & $73.4 \%$ & $81.8 \%$ & $80.0 \%$ & $82.8 \%$ & $78.5 \%$ & $77.3 \%$ & $83.2 \%$ & $80.1 \%$ & $78.8 \%$ & $79.5 \%$ \\
$60 \sim 69$ & $56.8 \%$ & $48.7 \%$ & $56.3 \%$ & $65.8 \%$ & $64.2 \%$ & $76.9 \%$ & $71.4 \%$ & $68.5 \%$ & $67.1 \%$ & $76.2 \%$ & $65.6 \%$ \\
$\geq 70$ & $16.7 \%$ & $25.0 \%$ & $16.7 \%$ & $31.3 \%$ & $17.6 \%$ & $42.9 \%$ & $43.8 \%$ & $28.0 \%$ & $19.0 \%$ & $38.1 \%$ & $28.3 \%$ \\
Stages & & & & & & & & & & & \\
I & $73.7 \%$ & $69.0 \%$ & $66.7 \%$ & $72.3 \%$ & $66.7 \%$ & $75.0 \%$ & $72.7 \%$ & $66.7 \%$ & $64.8 \%$ & $60.7 \%$ & $69.1 \%$ \\
II & $79.8 \%$ & $79.1 \%$ & $79.7 \%$ & $87.7 \%$ & $83.4 \%$ & $86.5 \%$ & $84.5 \%$ & $86.3 \%$ & $82.0 \%$ & $83.7 \%$ & $83.2 \%$ \\
III & $79.7 \%$ & $92.1 \%$ & $94.0 \%$ & $88.3 \%$ & $90.3 \%$ & $100.0 \%$ & $98.6 \%$ & $97.7 \%$ & $99.0 \%$ & $97.1 \%$ & $93.9 \%$ \\
HR status & & & & & & & & & & & $80.3 \%$ \\
ER+ and/or & $86.5 \%$ & $81.8 \%$ & $78.7 \%$ & $83.7 \%$ & $79.3 \%$ & $83.3 \%$ & $80.8 \%$ & $80.6 \%$ & $67.8 \%$ & $76.0 \%$ & $80.3 \%$ \\
PR+ & & & & & & & & & & \\
ER- and PR- & $82.4 \%$ & $83.9 \%$ & $92.7 \%$ & $88.1 \%$ & $86.0 \%$ & $87.6 \%$ & $92.9 \%$ & $76.5 \%$ & $83.9 \%$ & $81.3 \%$ & $85.3 \%$ \\
HER2 & & & & & & & & & & & $83 \%$ \\
status & & & & & & & & & & & $82 \%$ \\
Positive & $91.7 \%$ & $82.4 \%$ & $83.7 \%$ & $84.7 \%$ & $82.4 \%$ & $83.7 \%$ & $82.3 \%$ & $78.9 \%$ & $78.6 \%$ & $82.7 \%$ & $82.4 \%$ \\
Negative & $70.3 \%$ & $83.9 \%$ & $86.3 \%$ & $83.3 \%$ & $83.1 \%$ & $86.5 \%$ & $85.4 \%$ & $83.5 \%$ & $73.4 \%$ & $75.8 \%$ & $80.8 \%$ \\
\hline
\end{tabular}

$83.2 \%$ and $93.9 \%$, respectively. In lymph node positive and negative patients, 85.8\% (1628/1897) and $74.3 \%(1475 / 1984)$ received adjuvant chemotherapy, respectively. The percentage of adjuvant chemotherapy decreased from $73.7 \%$ in 1999 to $60.7 \%$ in 2008 in stage I disease, increased from $79.7 \%$ in 1999 to $97.1 \%$ in 2008 in stage III patients, and remained steady in stage II patients during this 10 years (Table 4).

Age

Of the 3271 patients who received adjuvant chemotherapy, $40.6 \%$ were diagnosed at the age between 40 and 49 years old, and $28.0 \%$ were between 50 and 59. From 1999 to 2008, the percentage of adjuvant chemotherapy in women younger than 60 years remained stable, while significantly increased in women between 60 and 69 and older than 70 years (increased from 56.8\% to $76.2 \%$ and from $16.7 \%$ to $38.1 \%$, respectively; Table 4). Age distribution of patients who received adjuvant chemotherapy was significantly different among different years $\left(\chi^{2}=32.2790, \mathrm{P}=0.0002\right)$.

For the entire population $(\mathrm{N}=4211)$, the age distribution was significantly different across years $(\mathrm{P}<0.0001)$. The percentages of patients in 30-39 and 4049 age groups were higher in 2008 than in 1999, while the percentage of older patients was lower in 2008 than in 1999.

\section{Hormone receptor status}

Among 3529 cases with hormone receptor (HR) testing, 2395 (67.9\%) patients were HR positive (ER and/ or PR positive). In HR positive and HR negative (ER and PR negative) patients, $80.3 \%$ and $85.3 \%$ received adjuvant chemotherapy, respectively. As illustrated in Table 4, the percentage of HR positive women who received adjuvant chemotherapy decreased from $86.5 \%$ in 1999 to $76.0 \%$ in 2008 , while in HR negative patients, this percentage remained stable.

\section{HER2 status}

HER2 testing was performed in $56.4 \%$ of patients in 1999 , which increased to $83.8 \%$ in 2008 . The southwest (38.3\%) and northwest $(43.5 \%)$ area had less patients tested for HER2 status compared to other regions. The HER2 positive (IHC $3+$ or FISH amplified) rate was $25.8 \%$ in 2849 patients who were tested for HER2. In HER2 positive and HER2 negative women, $82.4 \%$ and $80.8 \%$ received adjuvant chemotherapy, respectively. In 736 HER2 positive patients, only $19(2.6 \%)$ received adjuvant trastuzumab therapy, and the majority of them were diagnosed in 2007 (4 cases) and 2008 (10 cases). 


\section{Adjuvant chemotherapy regimens}

Among the 3271 patients who received adjuvant chemotherapy, 1258 (38.5\%) received anthracycline-based (without taxanes) regimens, $893(27.3 \%)$ received both anthracycline and taxane, and 449 (13.7\%) received CMF. The percentage of CMF decreased significantly during 1999-2008, and regimens containing both anthracyclines and taxanes increased significantly. The percentage of anthracycline-based (without taxanes) regimens increased in the first 5 years and decreased afterwards (Figure 1).

As shown in Supplementary Figure 1, 83.3\% of early stage breast cancer in the central area received both anthracyclines and taxanes in adjuvant therapy, which was extremely higher than in other areas (range from 5\% to $35 \%$ ). The percentage of anthracycline-based (without taxanes) regimens was the highest in the east area (54.4\%), and was the lowest in the central and southwest areas (12.7\% and $23.1 \%$, respectively). Significant differences were observed among 7 traditional regions of China $\left(\chi^{2}=\right.$ 32.2790, $\mathrm{P}=0.0002$ ).

Among 2151 patients treated with anthracyclines (with or without taxanes), 959 (44.6\%) received doxorubicin, and the rest $55.4 \%$ received epirubicin. The percentage of doxorubicin dropped from $92.1 \%$ in 1999 to $35.0 \%$ in 2008 , while the percentage of epirubicin increased from $7.9 \%$ to $65.0 \%$ (Figure 2). Comparing different regions, patients in the central and northwest areas received more doxorubicin $(94.5 \%$ and $58.1 \%$, respectively), while more epirubicin was applied in other regions.

Among 912 patients treated with taxanes in adjuvant therapy, $787(86.3 \%)$ received docetaxel, and the rest $13.7 \%$ received paclitaxel. Patients in the north area received more paclitaxel $(82.0 \%)$ than docetaxel, while patients in other regions received more docetaxel.

\section{Neoadjuvant chemotherapy}

A total of 558 (13.3\%) patients received neoadjuvant chemotherapy. The percentage of neoadjuvant chemotherapy increased from $10.4 \%$ in 1999 to $16.1 \%$ in 2008. More clinical T3 and T4 patients received neoadjuvant chemotherapy $(17.1 \%$ and $24.0 \%$, respectively); $8.2 \%$ and $24.1 \%$ of lymph node negative and positive patients received neoadjuvant chemotherapy, respectively.

In analysis of neoadjuvant regimens ( $\mathrm{n}=558), 48.3 \%$ were anthracycline-based (without taxanes) regimens, and $18.4 \%$ contained both anthracyclines and taxanes. From 1999 to 2008, the percentage of anthracycline-based regimens (without taxanes) increased in the first 5 years and decreased afterwards, while regimens containing both anthracyclines and taxanes increased constantly from 1999 through 2008 (Figure 3). The percentage of other regimens was the highest in 1999 and decreased afterwards. In regional comparison, $72.2 \%$ of patients in the central area received both anthracyclines and taxanes,

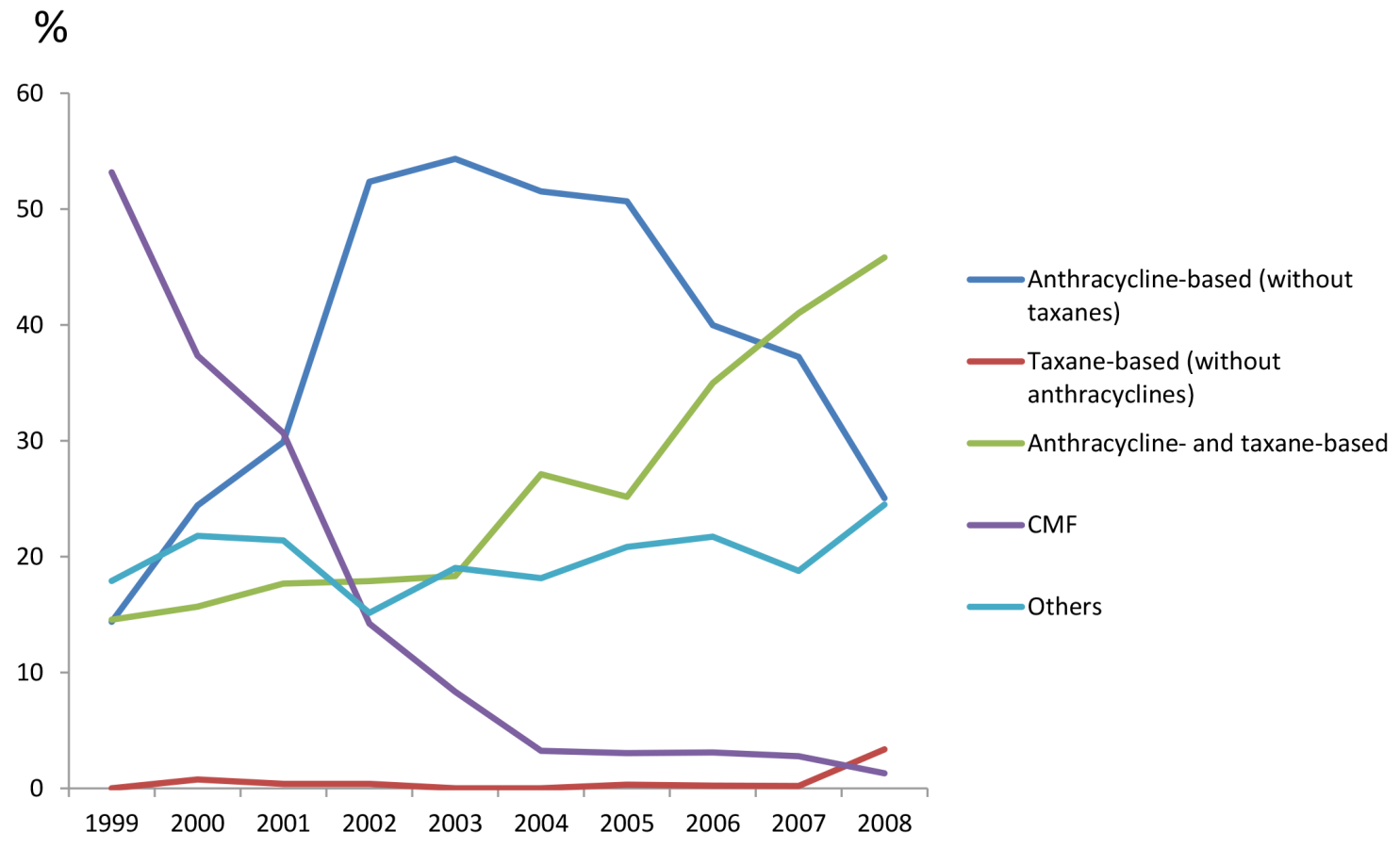

Figure 1: Percentage of adjuvant chemotherapy regimens for breast cancer treatment from 1999 to 2008 (after normalization of age). 
which was uncommon in the southwest $(9.2 \%)$ and the northeast (9.4\%) area (Supplementary Figure 2).

\section{Metastatic chemotherapy}

Among 4211 selected patients, only 392 (9.3\%) cases received chemotherapy in metastatic settings, and this percentage remained stable during this period (Table 1). A total of 327 patients received first-line chemotherapy. Among them, $41(12.5 \%)$ and 286 (87.5\%) patients received single-agent and combined chemotherapy, respectively. In 117 patients who received second-line chemotherapy, $23(19.7 \%)$ and 94 (80.3\%) patients received single-agent and combination chemotherapy, respectively.

The most frequently selected agents in first-line chemotherapy included taxanes $(27.2 \%)$, anthracyclines $(19.7 \%)$, platinum $(14.9 \%)$ and vinorelbine $(11.5 \%)$. In second-line regimens, taxanes $(22.4 \%)$ were also the most common choices, followed by platinum (19.2\%), capecitabine (15.1\%) and vinorelbine (14.2\%).

The most common combinations in first-line included anthracyclines plus taxanes (34.9\%), taxanes plus platinum (21.7\%) and vinorelbine plus platinum (16.5\%). In second-line treatment, taxanes and platinum (23.2\%) were most common combinations, followed by taxanes plus capecitabine $(21.7 \%)$ and vinorelbine plus platinum (18.8\%). Among 101 HER2 positive MBC patients, only $28(27.7 \%)$ received anti-HER2 treatment. Twenty-two patients received trastuzumab and 6 received lapatinib.

\section{DISCUSSION}

This is the first nation-wide multi-center epidemiologic study of chemotherapy in adjuvant, neoadjuvant and metastatic settings in Chinese breast cancer patients. This study described the transition and characteristics of chemotherapy as well as regional disparities in China from 1999 to 2008.

Major changes in adjuvant chemotherapeutic regimens were observed between 1999 and 2008. CMF regimen decreased rapidly from 1999 to 2004, and the percentage of anthracycline-based regimens increased and become the primary adjuvant regimen from 2001 to 2005. In the meantime, several publications including the EBCTCG meta-analysis demonstrated prognostic benefit of anthracycline-based regimens over CMF [7, 8]. After 2006, regimens containing both anthracyclines and taxanes became the mainstream. Simultaneously, multiple studies suggested that addition of taxanes was associated with more survival benefit compared to anthracyclines alone, especially in high-risk women [9].

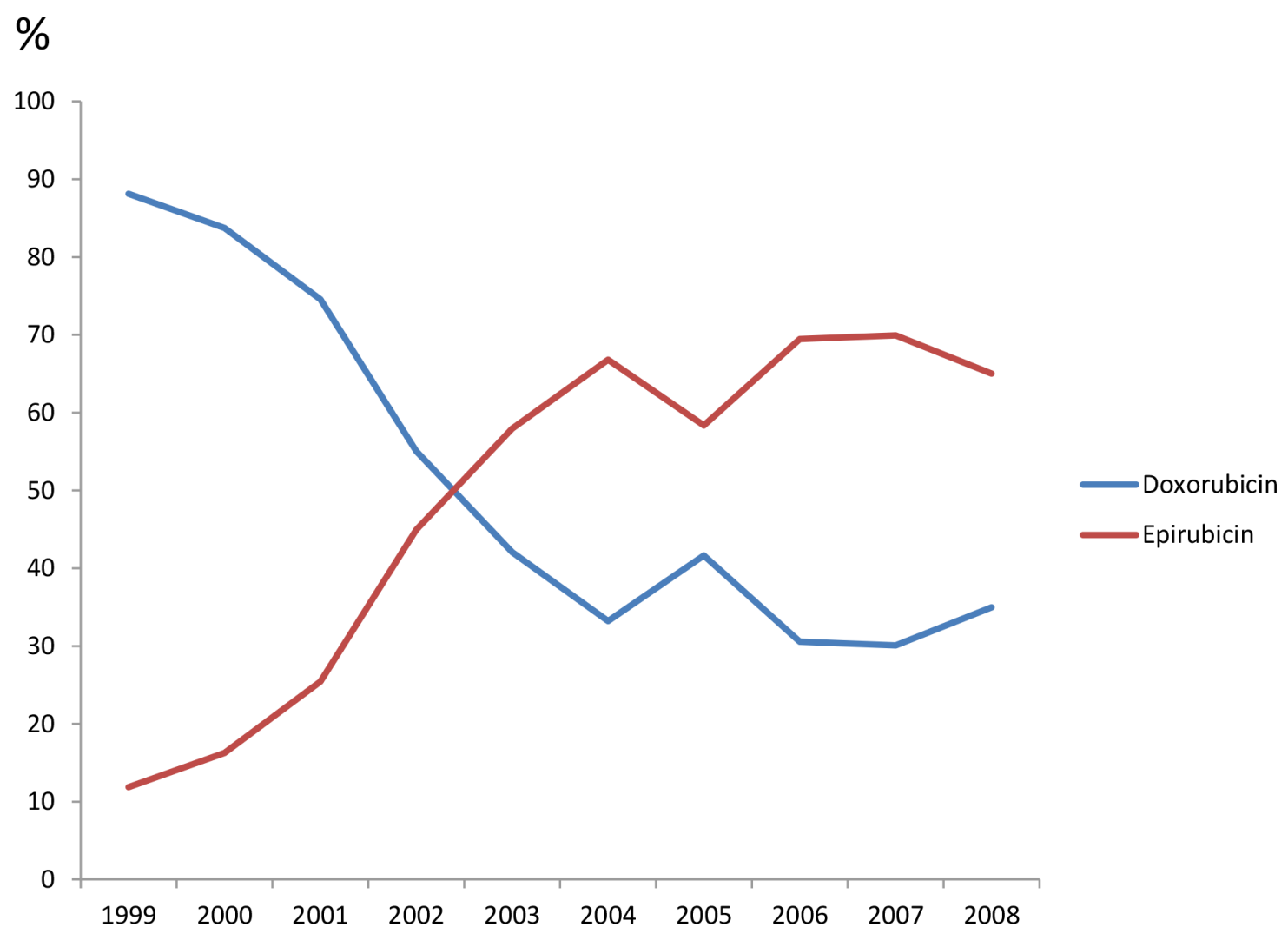

Figure 2: Percentage of doxorubicin and epirubicin in adjuvant chemotherapy regimens containing anthracyclines from 1999 to 2008. 
This transition of adjuvant chemotherapy in China (Figure 1) was 2 to 3 years later than that in other countries [10-12]. Based on contemporary observations from North America and Europe, regimens containing both anthracyclines and taxanes became the main choice since 2004 [10-12]. This delay was probably due to delayed entrance of taxanes into the drug reimbursement list in China [13].

Our analysis reported the transition from doxorubicin to epirubicin between 1999 and 2008, which reflected a better understanding of the differences between toxicity profiles, especially cardiotoxicities of these two drugs in China [14, 15].

Several independent factors were detected to affect the application of adjuvant chemotherapy. Similar to other studies $[16,17]$, primary tumor stages were associated with adjuvant chemotherapy application. The percentage of adjuvant chemotherapy in stage I patients decreased from 1999 to 2008, and increased in stage III cases. [18] This difference between stage I and stage III women in China reflected a transition from uniform treatment to differentiated and risk-adapted adjuvant chemotherapy based on evidence and international recommendations [18].

The percentage of early-stage patients who received adjuvant chemotherapy in our study was higher than western countries $[11,17,19]$. This difference could be explained by an earlier onset of breast cancer in China than in western countries. The median age at diagnosis was around 45 to 49 [20-22]. The percentage of patients younger than 35 years was higher in China [20-23]. Younger patients have better performance status and tolerance.

In our analysis, the percentage of HR positive women who received chemotherapy decreased during this 10 -year period. This transition reflected the evidence [2426] that adjuvant chemotherapy in HR positive patients was associated with smaller survival benefit than in HR negative patients.

The majority $(87.5 \%)$ of metastatic patients received combination regimens as first-line chemotherapy, which was significantly higher than in other countries $[12,27$, 28]. This preference for combination chemotherapy reflected the desire for rapid disease remission and better performance status and tolerance of Chinese breast cancer patients.

In addition to anthracyclines plus taxanes, platinumbased doublets were also frequently selected, such as taxanes plus platinum or gemcitabine plus platinum. Platinum was less expensive than many other agents and had synergistic activity with several agents [29-32]. Capecitabine was more common in second and third lines.

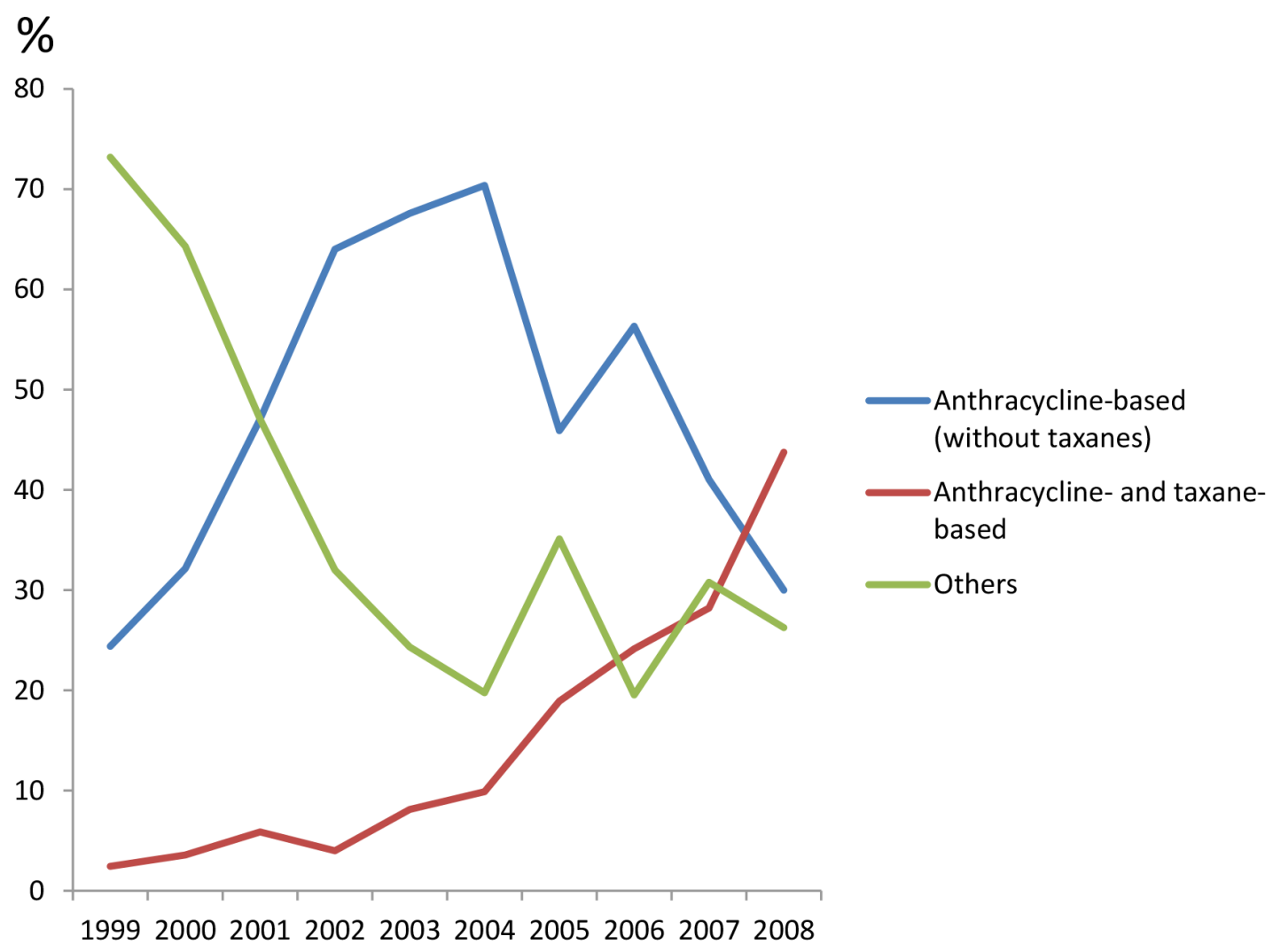

Figure 3: Percentage of neoadjuvant chemotherapy regimens for breast cancer treatment from 1999 to 2008. 
Enormous geographical differences were detected (Table 2). One possible reason would be socioeconomic discrepancies. The percentage of chemotherapy was higher in more prosperous eastern, southern and northern areas than other parts of China. The other reason would be diverse local health insurance policy. Paclitaxel, but not docetaxel, was covered by medical insurance in EBC patients in the north area, which greatly affected the selection of taxanes.

However, our analysis has several potential limitations. Firstly, selection bias might exist as no less elite hospitals were selected from the same area. Secondly, data quality was largely dependent on the thoroughness and accuracy of documentation of medical history and treatment. Thirdly, specific schedules, doses and side effects of certain chemotherapy regimens were not designed to be collected in this study. Finally, as an epidemiologic study, no survival follow-up was performed.

In conclusion, our study presented detailed information on characteristics and trends of chemotherapy regimens in Chinese breast cancer patients between 1999 and 2008. Stage, age, HR and HER2 status were all independent factors affecting decisions of chemotherapy in EBC women. The percentage of combination chemotherapy in advanced stage patients was higher than in Europe and North America. In addition, key findings from large clinical trials were incorporated into practice, but due to late access to new drugs and limitations of reimbursement policies, the evolution of regimens and agents were slower in China. Substantial geographical disparities could be attributed to regional socioeconomic inequalities and different health insurance policies.

\section{MATERIALS AND METHODS}

\section{Study design}

This study was a nation-wide multi-center retrospective epidemiologic study of randomly selected breast cancer patients over a 10-year interval in China. This study was approved by the Cancer Foundation of China Institutional Review Board.

\section{Hospital selection}

The hospital selection and case sampling methods have been previously described in detail [20]. According to traditional administrative district definition, China was stratified into 7 geographic regions (north, east, south, northeast, northwest, central and southwest). Convenience sampling was used to select one tertiary hospital from every region on the basis that (1) it was one of the best leading tertiary hospitals and had regional referral centers providing pathology diagnosis, surgery, radiotherapy, medical oncology, and routine follow-up care for patients with breast cancer; (2) inpatients were from all over the region; and (3) breast cancer screening practices were in accordance with Chinese national standards.

\section{Patients}

Female primary breast cancer inpatients in one randomly selected month each from year 1999 to 2008 were enrolled in this study. January and February were excluded due to Chinese annual holiday (the Spring Festival) [20]. In order to avoid selection bias, an enrolment scheme was used. Inpatients from alternating prespecified month of each year were enrolled. For example, in the year of 1999, pathology confirmed breast cancer patients admitted in March would be enrolled; in the year of 2000, patients admitted in Apirl would be enrolled. Beside, all patients in one selected month were reviewed. If inpatients in one selected month were less than 50 in that year, more cases from neighbor months were included until it reached 50 in total. To ensure this study to be geographically representative, we included patients from hospitals of all 7 regions across China.

All patients enrolled were required to meet the following inclusion criteria [20]: (1) pathologically confirmed primary breast cancer; (2) admission date was within the selected month in each hospital and (3) received treatment (surgery, medical therapy and/or radiotherapy) against breast cancer. Pathologic diagnosis of patients was based on the 1981 and 2003 WHO histological classification criteria [33, 34] and the 1997 and 2002 AJCC TNM staging systems $[35,36]$.

\section{Data collection and quality control}

As described previously [20], the following data were collected for all selected patients via medical chart review: (1) general information including date of diagnosis, inpatient admission date, diagnosis at admission, inpatient discharge date, and discharge outcome; (2) demographic characteristics including age, occupation, height, weight, education and marital status; (3) results of the clinical breast examination (CBE) and diagnostic imaging; (4) use of currently available surgery approaches, radiotherapy, chemotherapy and targeted therapy; (5) pathological characteristics including preoperative cytology and pathologic examinations, postoperative pathology, estrogen and progesterone receptor expressions and human epidermal growth factor receptor2 (HER-2) expression. All above information was recorded in the designed case report form (CRF) and was inspected for consistency [20].

\section{Statistical analysis}

Study participants were grouped according to 7 categories of regions (North, North-East, Central, South, 
East, North-west, and South-west) or year of diagnosis. We used the logistic regression model to examine the relations between adjuvant chemotherapy and its possible predictors. Tests for trend across the year of diagnosis for percentage of participants were performed using CochranArmitage Test. All $\mathrm{P}$ values were two-sided and $\mathrm{P}$ values less than 0.05 were considered statistically significant. Analyses were conducted using SAS version 9.1.3 service package 4 (SAS Institute Inc, Cary, NC).

\section{ACKNOWLEDGMENTS}

We thank the Cancer Institute of the Chinese Academy of Medical Sciences (CICAMS) for providing their expertise in the development of this study. We also thank the local investigators from Beijing, Liaoning (Shenyang), Hunan (Changsha), Guangdong (Guangzhou), Zhejiang (Hangzhou), Shannxi (Xian), and Sichuan (Chengdu) for data collection and assisting us with completing this project successfully.

\section{CONFLICTS OF INTEREST}

No potential conflicts of interest were disclosed.

\section{GRANT SUPPORT}

We thank Pfizer for funding.

\section{REFERENCES}

1. Bonadonna G, Valagussa P, Moliterni A, Zambetti M, Brambilla C. Adjuvant cyclophosphamide, methotrexate, and fluorouracil in node-positive breast cancer: the results of 20 years of follow-up. N Engl J Med. 1995; 332: 901-6.

2. Lopez-Tarruella S, Martin M. Recent advances in systemic therapy: advances in adjuvant systemic chemotherapy of early breast cancer. Breast Cancer Res. 2009; 11: 204.

3. Ring AE, Ellis PA. Taxanes in the treatment of early breast cancer. Cancer Treat Rev. 2005; 31: 618-27.

4. Henderson IC, Berry DA, Demetri GD, Cirrincione CT, Goldstein LJ, Martino S, Ingle JN, Cooper MR, Hayes DF, Tkaczuk KH, Fleming G, Holland JF, Duggan DB. Improved outcomes from adding sequential Paclitaxel but not from escalating Doxorubicin dose in an adjuvant chemotherapy regimen for patients with node-positive primary breast cancer. J Clin Oncol. 2003; 21: 976-83.

5. Tkaczuk KH. Review of the contemporary cytotoxic and biologic combinations available for the treatment of metastatic breast cancer. Clin Ther. 2009; 31 Pt 2: 2273-89.

6. Untch M, Konecny GE, Paepke S, von MG. Current and future role of neoadjuvant therapy for breast cancer. Breast. 2014; 23: 526-37.
7. Early Breast Cancer Trialists' Collaborative Group (EBCTCG). Effects of chemotherapy and hormonal therapy for early breast cancer on recurrence and 15-year survival: an overview of the randomised trials. Lancet. 2005; 365: 1687-717.

8. Paik S, Bryant J, Tan-Chiu E, Yothers G, Park C, Wickerham DL, Wolmark N. HER2 and choice of adjuvant chemotherapy for invasive breast cancer: National Surgical Adjuvant Breast and Bowel Project Protocol B-15. J Natl Cancer Inst. 2000; 92: 1991-8.

9. Nowak AK, Wilcken NR, Stockler MR, Hamilton A, Ghersi D. Systematic review of taxane-containing versus nontaxane-containing regimens for adjuvant and neoadjuvant treatment of early breast cancer. Lancet Oncol. 2004; 5: 372-80.

10. Shen Y, Dong W, Feig BW, Ravdin P, Theriault RL, Giordano SH. Patterns of treatment for early stage breast cancers at the M. D. Anderson Cancer Center from 1997 to 2004. Cancer. 2009; 115: 2041-51.

11. Vaz-Luis I, Hughes ME, Cronin AM, Rugo HS, Edge SB, Moy B, Theriault RL, Hassett MJ, Winer EP, Lin NU. Variation in type of adjuvant chemotherapy received among patients with stage I breast cancer: a multi-institutional study. Cancer. 2015; 121: 1937-48.

12. van Herk-Sukel MP, van de Poll-Franse LV, Creemers GJ, Lemmens VE, van der Linden PD, Herings RM, Coebergh JW, Voogd AC. Major changes in chemotherapy regimens administered to breast cancer patients during 2000-2008 in the Netherlands. Breast J. 2013; 19: 394-401.

13. Suvarna N. Information and insight into breast cancer in China. http:/www.kantarhealth.com/docs/white-papers/ information-andinsight-into-breast-cancer-in-china.pdf.

14. Jain KK, Casper ES, Geller NL, Hakes TB, Kaufman RJ, Currie V, Schwartz W, Cassidy C, Petroni GR, Young CW. A prospective randomized comparison of epirubicin and doxorubicin in patients with advanced breast cancer. J Clin Oncol. 1985; 3: 818-26.

15. Kaklamani VG, Gradishar WJ. Epirubicin versus doxorubicin: which is the anthracycline of choice for the treatment of breast cancer. Clin Breast Cancer. 2003; 4: S26-33.

16. Hassett MJ, Hughes ME, Niland JC, Edge SB, Theriault RL, Wong YN, Wilson J, Carter WB, Blayney DW, Weeks JC. Chemotherapy use for hormone receptor-positive, lymph node-negative breast cancer. J Clin Oncol. 2008; 26: 5553-60.

17. Harlan LC, Clegg LX, Abrams J, Stevens JL, BallardBarbash R. Community-based use of chemotherapy and hormonal therapy for early-stage breast cancer: 1987-2000. J Clin Oncol. 2006; 24: 872-7.

18. Goldhirsch A, Wood WC, Gelber RD, Coates AS, Thurlimann B, Senn HJ. Meeting highlights: updated 
international expert consensus on the primary therapy of early breast cancer. J Clin Oncol. 2003; 21: 3357-65.

19. Joerger M, Thurlimann B, Savidan A, Frick H, Bouchardy C, Konzelmann I, Probst-Hensch N, Ess S. A populationbased study on the implementation of treatment recommendations for chemotherapy in early breast cancer. Clin Breast Cancer. 2012; 12: 102-9.

20. Li J, Zhang BN, Fan JH, Pang Y, Zhang P, Wang SL, Zheng S, Zhang B, Yang HJ, Xie XM, Tang ZH, Li H, Li JY, et al. A nation-wide multicenter 10-year (1999-2008) retrospective clinical epidemiological study of female breast cancer in China. BMC Cancer. 2011; 11: 364.

21. Fan L, Zheng Y, Yu KD, Liu GY, Wu J, Lu JS, Shen KW, Shen ZZ, Shao ZM. Breast cancer in a transitional society over 18 years: trends and present status in Shanghai, China. Breast Cancer Res Treat. 2009; 117: 409-16.

22. Yuan XM, Wang N, Ouyang T, Yang L, Song MY, Lin BY, Xie YT, Li JF, Pan KF, You WC, Zhang L. Current status of diagnosis and treatment of primary breast cancer in beijing, 2008. Chin J Cancer Res. 2011; 23: 38-42.

23. Fan L, Strasser-Weippl K, Li JJ, St Louis J, Finkelstein DM, Yu KD, Chen WQ, Shao ZM, Goss PE. Breast cancer in China. Lancet Oncol. 2014; 15: e279-89.

24. Berry DA, Cirrincione C, Henderson IC, Citron ML, Budman DR, Goldstein LJ, Martino S, Perez EA, Muss HB, Norton L, Hudis C, Winer EP. Estrogen-receptor status and outcomes of modern chemotherapy for patients with nodepositive breast cancer. JAMA. 2006; 295: 1658-67.

25. Roche H, Fumoleau P, Spielmann M, Canon JL, Delozier T, Serin D, Symann M, Kerbrat P, Soulié P, Eichler F, Viens P, Monnier A, Vindevoghel A, et al. Sequential adjuvant epirubicin-based and docetaxel chemotherapy for nodepositive breast cancer patients: the FNCLCC PACS 01 Trial. J Clin Oncol. 2006; 24: 5664-71.

26. Colleoni M, Li S, Gelber RD, Coates AS, CastiglioneGertsch M, Price KN, Lindtner J, Rudenstam CM, Crivellari D, Collins J, Pagani O, Simoncini E, Thürlimann $\mathrm{B}$, et al. Timing of CMF chemotherapy in combination with tamoxifen in postmenopausal women with breast cancer: role of endocrine responsiveness of the tumor. Ann Oncol. 2005; 16: 716-25.
27. Carrick S, Parker S, Thornton CE, Ghersi D, Simes J, Wilcken N. Single agent versus combination chemotherapy for metastatic breast cancer. Cochrane Database Syst Rev. 2009; CD003372.

28. Cardoso F, Bedard PL, Winer EP, Pagani O, SenkusKonefka E, Fallowfield LJ, Kyriakides S, Costa A, Cufer T, Albain KS; ESO-MBC Task Force. International guidelines for management of metastatic breast cancer: combination vs sequential single-agent chemotherapy. J Natl Cancer Inst. 2009; 101: 1174-81.

29. Sacchi A, Gasparri A, Gallo-Stampino C, Toma S, Curnis F, Corti A. Synergistic antitumor activity of cisplatin, paclitaxel, and gemcitabine with tumor vasculature-targeted tumor necrosis factor-alpha. Clin Cancer Res. 2006; 12: 175-82.

30. Li Q, Li Q, Zhang P, Yuan P, Wang J, Ma F, Luo Y, Fan Y, Cai R, Xu B. A phase II study of capecitabine plus cisplatin in metastatic triple-negative breast cancer patients pretreated with anthracyclines and taxanes. Cancer Biol Ther. 2015; 16: 1746-53.

31. Heinemann V, Stemmler HJ, Wohlrab A, Bosse D, Losem C, Kahlert S, Rauthe G. High efficacy of gemcitabine and cisplatin in patients with predominantly anthracyclineand taxane-pretreated metastatic breast cancer. Cancer Chemother Pharmacol. 2006; 57: 640-6.

32. Zhang J, Fan M, Xie J, Wang Z, Wang B, Zhang S, Wang L, Cao J, Tao Z, Li T, Hu X. Chemotherapy of metastatic triple negative breast cancer: Experience of using platinum-based chemotherapy. Oncotarget. 2015; 6:43135-43143. https:// doi.org/10.18632/oncotarget.5654.

33. WHO. Histological typing of breast tumors. 1981; Geneva: World Health Organization.

34. Tavassoli FA, Devilee P. Pathology and genetics of tumours of the breast and female genital organs. 2003; Lyon: World Health Organization.

35. Fleming ID. American Joint Committee on Cancer: AJCC cancer staging manual. 1997; Philadelphia: LippincottRaven Philadelphia.

36. Greene FL. American Joint Committee on Cancer: AJCC cancer staging manual. 2002; New York: Springer Verlag. 